can bind to anti-myelin antibodies ${ }^{13}$. Many other viruses-including herpesviruses such as Epstein-Barr virus-also bind to DR2. Thus, microbial peptides could trigger an autoimmune response against myelin in humans. The inflammatory response may be self-perpetuating after an infectious agent has been cleared (or has become latent), because MBP and other myelin proteins are released as the result of myelin destruction. This may explain why Soldan et al. ${ }^{2}$ could amplify HHV-6 DNA from only 15 of $50 \mathrm{MS}$ patients.

Molecular mimicry provides a scheme whereby viral sensitization in the blood leads to activation of $T$ cells. These enter the brain where they may cause destruction when they encounter their cognate mimic in myelin (see figure). Molecular mimicry also allows for reconciliation of the "genes versus the environment" debate: the most important gene in determining susceptibility to MS - that is, HLA-is critical for selecting the appropriate mimic and presenting it to the immune system. Moreover, many different viruses mimic various parts of the myelin sheath, so inflammation in the white matter of the brain may ensue from an immune response to a variety of microbes. Thus, the hope of finding the virus that triggers MS may remain elusive forever.

1. Karpuj, M.V., Steinman, L. \& Oksenberg, J.R. Multiple sclerosis: a polygenic disease involving epistatic interactions, germline rearrangements and environmental effects. Neurogenetics 1, 21-28 (1997).

2. Soldan, S.S. et al. Association of human herpesvirus-6 (HHV-6) with multiple sclerosis: increased $\lg M$ response to HHV- 6 early antigen and detection of serum HHV-6 DNA. Nature Med. 3, 1394-1397 (1997).

3. Ebers, G.C. et al. A population-based study of multiple sclerosis in twins. N. Engl. J. Med. 315, 151-157 (1986).

4. Kurtzke, |.F. Epidemiology of MS. Multiple Sclerosis (eds Hallpike, J.F., Adams, C.W.M. \& Tourtellote, W.E.) 49-95 (Williams and Wilkins, Baltimore MD, 1983).

5. Secchiero, P. et al. Detection of human herpesvirus 6 in prasma of children with primary infection and immunosuppressed patients by polymerase chain reaction. I. Infect. Dis. 171, 273-280 (1995).

6. Ganem, D. KSHV and Kaposi's sarcoma: the end of the beginning? Cell 91, 157-160 (1997).

7. Challoner, P.B. et al. Plaque-associated expression of human herpesvirus 6 in multiple sclerosis. Proc. Natl Acad. Sci. USA 92, 7440-7444 (1995).

8. Brocke, S. et al. Induction of relapsing paralysis in experimental autoimmune encephalomyelitis by bacterial superantigen. Nature 365, 642-644 (1993).

9. Conrad, B. et al. A human endogenous retroviral superantigen as candidate autoimmune gene in type I diabetes. Cell 90, 303-313 (1997).

10. Perron, $H$. et al. Molecular identification of a novel retrovirus repeatedly isolated from patients with multiple sclerosis. Proc. Natl. Acad. Sci. USA 94, 7583-7588 (1997).

11. Oldstone, M.A. Molecular mimicry and autoim- mune disease. Cell 50, 819-820 (1997)

12. Wucherpfennig, K. \& Strominger, J. Molecular mimicry in $T$ cell-mediated autoimmunity: viral peptides activate human $T$ cell clones specific for myelin basic protein. Cell, 80, 695-705 (1995).

13. Wucherpfenig, K.W. et al. Recognition of the immunodominant myelin basic protein peptide by autoantibodies and HLA-DR2 restricted $T$ cell clones from multiple sclerosis patients: identity of key contact residues in the B-cell and T-cell epitopes. J. Clin. Invest. 100, 1114-1122 (1997).
${ }^{1}$ Department of Neurological Sciences

Beckman Center for Molecular and

Genetic Medicine

Stanford, California 94305, USA

${ }^{2}$ Department of Neuropharmacology

Division of Virology, The Scripps Research Institute

La Jolla, California 90237, USA

\title{
Puzzling over prion partners
}

To understand what goes wrong in disease, we often need to know how the biological systems usually operate and work backward from there. The study of transmissible spongiform encephalopathies (TSEs) - such as bovine spongiform encephalopathy, Creutzfeldt-Jakob disease and scrapie-is no exception. Here, the search hinges on the normal function of the cellular prion protein $\operatorname{PrP}^{c}$, and two papers in this issue may provide a means to that end by identifying possible receptors for this protein.

The main principle of the "proteinonly" hypothesis is that a cell-membrane glycoprotein called $\mathrm{PrP}^{\mathrm{C}}$ is converted to a misfolded, pathological form designated $\mathrm{PrP}^{*}$. The conversion is almost always accompanied by the formation of a protease-resistant molecule $\left(\operatorname{Pr} P^{\mathrm{sc}}\right)$, and the ultimate result is cell death. But how and why does this happen? And what does $\operatorname{PrP}^{C}$ normally do?

Found in the brains of all vertebrates examined so $\mathrm{far}, \operatorname{Pr} \mathrm{PC}^{\mathrm{C}}$ is anchored to the plasma membrane by a glycosyl-phosphatidylinositol moiety. So it comes as no surprise that both of the newly identified putative $\operatorname{PrP}^{c}$ receptors are membranebound proteins. In the first study, Martins et al. (page 1376) used a technique called complementary hydropathy-the theory being that peptides encoded by complementary DNA strands will bind one another-to make a 16-amino-acid complementary peptide to the neurotoxic region of $\operatorname{PrP}^{C}$. By raising antibodies against this peptide and probing mouse neurons, they identified a 66 $\mathrm{kDa}$ membrane protein that binds $\operatorname{Pr} \mathrm{PC}^{\mathrm{C}}$ both in vitro and in vivo.

Rieger et al. (page 1383) took a differ-

\section{IMAGE \\ UNAVAILABLE FOR COPYRIGHT REASONS}

ent approach, using a yeast two-hybrid screen to identify proteins that interact with $\operatorname{PrP}^{c}$. They pulled out the $37-\mathrm{kDa}$ laminin receptor precursor protein (LRP) - a membrane-bound protein that mediates the action of laminin on neurons, and is highly conserved among mammals. Shown in the picture are neuroblastoma cells incubated with anti-LRP antibodies (the dense circle around the cells indicates that LRP is localized to the surface). LRP was found in all of the organs that are associated with prion propagation, and increased concentrations of LRP correlated with the accumulation of $\operatorname{Pr} P^{\text {Sc }}$ in mice and hamsters.

Size alone indicates that the receptors identified by Martins et al. and Rieger et al. are probably not the same, although the LRP is thought to homodimerize in vivo to form the $67-\mathrm{kDa}$ highaffinity laminin receptor. At present, it's impossible to say whether either of these proteins is the physiological receptor for $\mathrm{PrP}^{\mathrm{C}}$, or even to speculate what $\operatorname{Pr}^{\mathrm{C}}$ may do when it interacts with them. But, as long as we don't know what the function of $\operatorname{PrP}^{C}$ is, any of its molecular interactions are very relevant to the study of prion diseases.

ALISON MiTCHELL

Alison Mitchell is an assistant editor of Nature 